\title{
Morphological development of river widenings with variable sediment supply
}

\author{
Cristina Rachelly ${ }^{1, *}$, Volker Weitbrecht ${ }^{1}$, David F. Vetsch ${ }^{1}$, and Robert M. Boes ${ }^{1}$ \\ ${ }^{1}$ Laboratory of Hydraulics, Hydrology and Glaciology (VAW), Swiss Federal Institute of Technology \\ Zurich (ETH Zurich), Zurich, Switzerland
}

\begin{abstract}
River widening is a common restoration approach to mitigate the adverse effects of past stream alterations on infrastructure and the riparian ecosystem by stabilizing the river bed and enhancing habitat heterogeneity. In this study, two river widening approaches, excavated and dynamic, are described for the case of moderately steep gravel-bed rivers in the Alpine foothills, with a focus on dynamic river widening. As most channelized rivers exhibit ongoing degradation due to the lack of sediment supply and efforts to restore sediment transport are increasing, the consideration of the response of river widenings to variable sediment supply is important. For this purpose, insights from regime theory are applied to river widening and several experimental flume and field studies on channel response to variable sediment supply are reviewed. Dynamic river widenings are expected to be morphologically active in weakly degraded rivers with sufficient sediment supply, while they may not be an appropriate restoration approach for highly degraded rivers due to persistent impairment of morphological activity.
\end{abstract}

\section{Introduction}

Over the course of the past decades and centuries, human impacts have fundamentally changed stream characteristics like flow regime, sediment supply, and channel geometry [13]. Systematic flood protection has gained importance during the 19th century, as the need for agriculture and settlement land due to rapid population growth increased the pressure on previously unoccupied wetlands in the alluvial plains [1]. Numerous rivers were straightened and channelized to ensure rapid downstream conveyance of water and sediment $[2,4,5]$. Other land-use changes, e.g. in forest management, have indirectly affected streams by altering erosion rates and thus the sediment supply to the stream [6]. During the 1950s-70s, the construction of dams, transverse barriers in torrents, and sediment retention basins along with extensive sediment extraction further impacted the hydrodynamics and sediment transport in streams [1, 5-7].

The widespread impairment and imbalance of flow and sediment discharge has severe consequences for the riparian ecosystem, such as channel narrowing and incision, disconnection of floodplains, loss of fish spawning habitat, or clogging [2, 3]. In general, the hydraulic and morphological dynamics and heterogeneity are reduced. Various aquatic and terrestrial

\footnotetext{
*e-mail: rachelly@vaw.baug.ethz.ch
} 

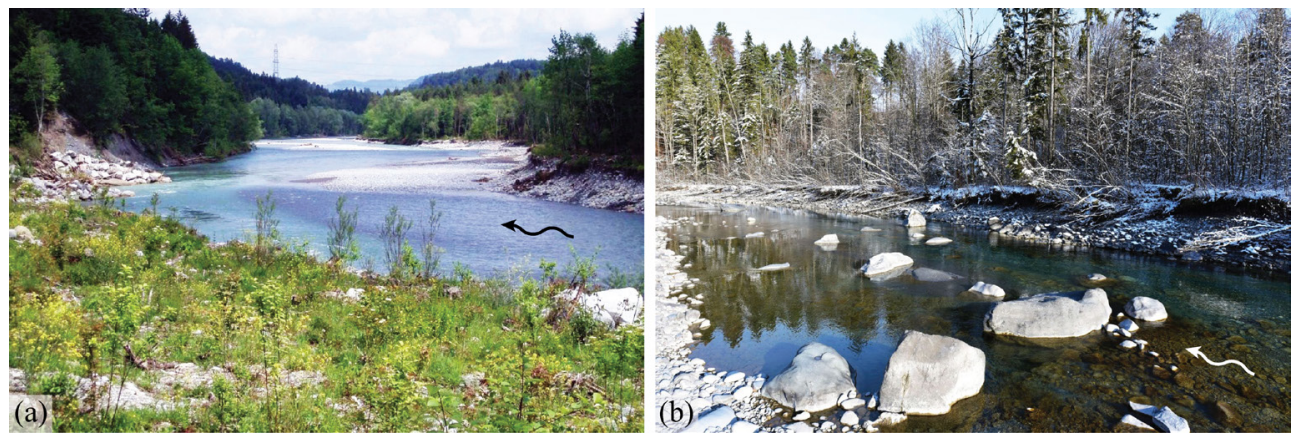

Figure 1. (a) Pioneer vegetation on gravel bars (Tiefbauamt des Kantons Bern, Oberingenieurkreis I, Kander Augand, 2006) and (b) dynamic bank erosion processes in the river widening Augand along the Kander River, an alpine gravel-bed river in Switzerland.

species are sensitive to changes of grain size distribution and rely on floods with bed mobility as episodic disturbances [8]. Efforts to mitigate these adverse effects have increased since the 1990s [9] and recent adaptions of the legal framework in many countries have initiated long-term restoration programs (e.g. Swiss Federal Act on the Protection of Waters 1991, EU Water Framework Directive 2000).

A multitude of restoration strategies and measures can be applied [10,11]. An analysis of more than 37'000 restoration projects in the U.S. showed that channel re-configuration and in-stream habitat improvements are among the most common restoration goals [12]. Local river widening is a restoration measure based on the premise that providing more space for morphodynamic processes will increase habitat heterogeneity, i.e. variable grain sizes, water depths, and flow velocities, which will in turn increase the abundance and diversity of biota [8] (Fig. 1). The study of the effects of variable sediment supply on river widenings is motivated by the ongoing degradation of many channelized rivers, but also the increasing efforts to restore sediment transport continuity. The term sediment is hereby used interchangeably with bed material, whereas the wash load fraction is not explicitly considered [13].

Following a short overview of general regime theory and transient channel response, several studies on the effects of variable sediment transport on channels are reviewed. These general findings are then applied to river widening in alluvial gravel-bed rivers and the test program of a research project on this topic is outlined.

This review is part of the Swiss interdisciplinary research program Riverscapes (see Acknowledgements) that aims to enhance the understanding of sediment dynamics and the lateral connectivity of rivers with their floodplains.

\section{Transient channel response}

According to Mackin [14] and Lane [15], a river at grade adjusts its slope so that the imposed sediment load of a certain grain size distribution can just be transported by the available discharge. Lane [15] formulated the qualitative relation $Q_{b} d_{b} \propto Q S$ with sediment load $Q_{b}$, grain size diameter $d_{b}$, discharge $Q$, and stream slope $S$. The concept of grade provides a helpful conceptual model of stream response to hydrological and geomorphic changes of natural or anthropogenic origin and was refined in many variations of regime theory [16].

Eaton and Church [17] extended the original formula by Lane [15] with the mean water depth $h$ and the dimensionless critical shear stress $\theta_{c}$ : 


$$
\frac{Q_{b}}{Q S} \propto\left[\frac{h S}{d_{b} \theta_{c}}\right]^{(3 / 2) x_{1}}
$$

Eq. (1) identifies possible adjustment processes to a change in $Q$ or $Q_{b}$ : changes in channel shape are included in the mean water depth $h$ [13]; aggradation, degradation, and changes in sinuosity are included in the stream slope $S[4,6,18]$; the degree of armoring is included in the surface grain size $d_{b}$ [19]; and surface structures are included in the dimensionless critical shear stress $\theta_{c}$ [13] (Fig. 2). The exponent $x_{1}$ decreases for higher relative stream power, which indicates that the relative importance of surface grain size, surface structure, and channel shape is more pronounced for gravel-bed rivers with low relative stream power as compared to sand-bed rivers with high relative stream power [17].

A similar regime approach was formulated by Eaton et al. [20], following the premise that alluvial systems will maximize their system flow resistance $f_{s y s}$, which is the sum of the grain resistance $f^{\prime}$, the within-channel form resistance $f^{\prime \prime}$, and the reach-scale form resistance due to sinuosity $f^{\prime \prime \prime}$. It follows that a river generally has three degrees of freedom to adjust to any changes in flow regime and sediment supply.

Although these models strongly support our understanding of the general direction of channel alterations, their simplicity and integrative nature cannot fully represent the large variability in many parameters and the multiple interacting and dynamic processes [16]. Variations of bank stability due to variable grain sizes, cohesion, and vegetation are usually not included in these models, regardless their importance in channel formation [21-23]. Mackin [14] also addressed the importance of temporal scale by comparing responses to natural alterations, which occur over hundreds or thousands of years, to anthropogenic changes, which cause channel adjustment of 'almost telegraphic rapidity' ([14], p. 464). These possibly severe, transient channel adjustments are owed to the high intensity of anthropogenic alterations occurring over short durations in contrast to natural shifts in a watershed $[5,16]$.

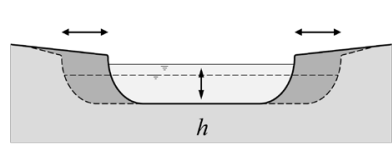

(a)

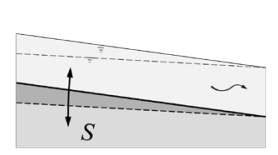

(b)
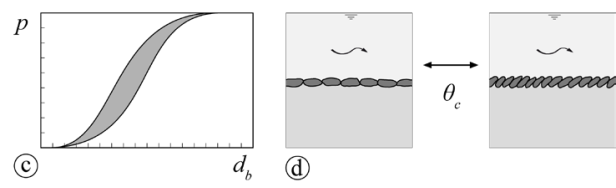

Figure 2. Possible channel adjustments to variable discharge $Q$ and sediment supply $Q_{b}$ according to Eaton and Church [17] with (a) mean water depth $h$, (b) channel slope $S$, (c) surface grain size $d_{b}$, and (d) dimensionless critical shear stress $\theta_{c}$.

\section{Variable sediment supply in channels}

If the supply of sediment to an otherwise unchanged alluvial stream is interrupted or reduced below its transport capacity, excess stream power can entrain sediment from the bed and the banks. According to Eq. (1), there are four possible channel adjustments following a reduction or increase in sediment supply in an otherwise unchanged alluvial stream.

Several experimental flume and field studies investigated the effects of reduced sediment supply to identify the dominant adjustment process. Dietrich et al. [24] and Nelson et al. [25] described flume experiments with a plane bed and reported vertical channel degradation, surface coarsening, the expansion of inactive patches confining the active sediment transport zone, and the eventual loss of all bed surface heterogeneity as the primary response to reduced 
sediment supply. Analogous experiments with alternate bars observed significant channel incision, coarsening in the pools, and concurrent emergence of the bar tops [26, 27] with surface coarsening eventually limiting bed degradation [6]. Venditti et al. [28], however, described the degradation of alternate bars either by migrating out of the channel or by vertical erosion, resulting in a plane bed. The contrasting behavior was explained with different values of relative submergence of the bar tops and it was concluded that bar emergence will more likely occur, especially if the decrease of sediment supply is accompanied by a reduction of peak flows [29]. This is a realistic scenario for river reaches below storage power plants. Surian and Rinaldi [5] compiled field studies on the adjustments of Italian rivers to reduced sediment supply during the last century. They identified narrowing and incision to be the primary channel responses, with braided rivers predominantly narrowing and single-thread rivers predominantly incising. Rollet et al. [30] successfully linked channel bed incision, decreased bar area during low flows, and surface coarsening to the construction of a dam along the Ain River in France. In conclusion, channel degradation, narrowing of the active bed load transport zone, and surface coarsening seem to be the primary channel response to reduced sediment supply, especially in channelized rivers with impaired lateral mobility.

An increase in sediment supply will to some extent reverse these processes. Eaton and Church [32] found that channelized rivers can accommodate up to a fourfold increase of sediment supply by adjusting their surface texture. Madej et al. [6] reported surface fining, channel widening and mid-channel bar formation, and a less pronounced relief after increasing the sediment supply to a flume with degraded, armored alternate bars. The preferential deposition of sediment in pools and the concurrent reduction in cross-sectional relief was also observed by Bankert and Nelson [27] and Friedl [33]. However, if sediment supply is further increased and pools fill up beyond a certain threshold, steady bars can be eroded and washed out, whereby the bed is reworked and new bars will eventually develop [27]. In conclusion, the primary channel response to an increase in sediment supply is surface fining, deposition in pools and bar formation, while fully dynamic states with significant lateral mobility can only be reached after sufficient aggradation.

Regime models are certainly not sufficient to explain the range of observed channel responses to variable sediment supply due to additional influences of hydrology, vegetation, and sedimentology [16]. The persistence of bedforms during increasing or decreasing sediment supply strongly depends on the local distribution of boundary shear stress relative to critical shear stress [26-28]. As the distribution of boundary shear stress is stage-dependent, the consideration of the hydrological regime and morphological history is indispensable for a thorough analysis of a channel response [27].

These considerations provide a conceptual framework for the following assessment of the morphological effects of variable sediment supply on river widenings.

\section{River widenings}

River widenings of defined longitudinal and lateral extent can be implemented in an excavated or dynamic manner $[34,35]$. The goals of river widenings are the (1) suspension of vertical bed degradation, (2) promotion of dynamic morphological processes to create diverse aquatic and terrestrial habitats, (3) enhancement of abundance and biodiversity of flora and fauna, and (4) lowering of flood stage (not discussed here) [9].

\subsection{Excavated river widenings}

With a focus on the suspension of ongoing vertical bed degradation, early river widenings were seen as a viable alternative to the construction of sills and weirs [36]. They were ex- 
cavated to their final width and the newly created banks were protected by groins or riprap. Here, excavated river widenings are defined as a mere widening of a river bed, whereas they can also be constructed with an anticipated bed elevation offset within the widened section. Hunzinger [36] described their morphological development based on the results of hydraulic flume experiments. In general, an excavated river widening represents an abrupt disturbance of channel geometry that provokes a rapid morphological reaction and a temporary interruption of sediment continuity due to deposition within the widened reach. The spatial and temporal evolution of the subsequent equilibration process is strongly dependent on the size of the river widening, the flow regime, and the sediment supply level [9]. River widenings in eroding rivers cannot prevent further bed erosion [37].

\subsection{Dynamic river widenings}

Recently, the re-establishment of dynamic morphological processes has gained importance in river restoration. Instead of widening a river segment by excavation, the bank protection structures along a limited length of a channelized river are removed, thereby promoting lateral mobility by bank erosion and aggradation (i.e. dynamic river widening). Usually, the channel is initially widened to induce bank erosion through bar formation and subsequent lateral flow diversion. Alternative methods to induce bank erosion, e.g. the placement of artificial bars to deflect flow towards the bank, have been described by Friedl [33] and Aufleger et al. [9].

Lateral mobility depends on active bank erosion [38]. Fig. 3 shows the temporal evolution of a dynamic river widening in Switzerland where active bank erosion was observed and large, mostly unvegetated bars have formed. Since infrastructure and property have to be protected, the planning practice in Switzerland comprises the definition of both an observation line and an intervention line [39]. When bank erosion reaches the observation line, the topographic monitoring is intensified, and possible protection measures are planned. The intervention line marks the outermost boundary of the river widening and has to be defended by bank protection structures like groins or riprap.

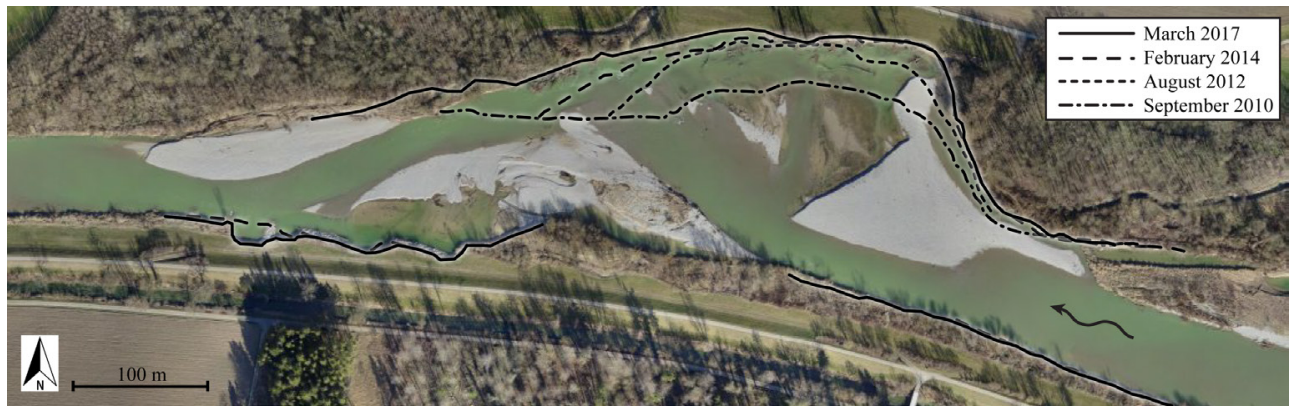

Figure 3. The lower part of the $1700 \mathrm{~m}$ long dynamic river widening Schäffäuli along the Thur River in 2016. The channel of $50 \mathrm{~m}$ width was initially widened in 2003 and has eroded $26000 \mathrm{~m}^{2}$ land until 2015 (Orthophoto and data: geotopo ag (Breitenstrasse 16, CH-8501 Frauenfeld, www.geotopo.ch)).

Dynamic river widenings have some advantages over conventional, excavated widenings. As the widening process is mostly left to the river, sediment remains within the channel, and the discrepancy between transport capacity and sediment supply will not grow as large as for excavated widenings. Dynamic river widenings also require less technical bank protection structures as they are only constructed where necessary, reducing construction costs and 
maintaining natural banks where possible. Compared to excavated river widenings, the uncertain temporal evolution of dynamic river widenings and the potential threat due to hazardous bank erosion may lower their public acceptance.

\section{Effects of variable sediment supply on dynamic river widenings}

River widenings are characterized by a locally increased channel width and resulting local morphological adjustments [40]. Dynamic river widenings are more likely to display a barpool morphology than fully developed braiding, due to their limited spatial extent and the degradational state commonly associated with channelized gravel-bed rivers [29]. This assumption is supported by reports on several dynamic river widenings in Austria and Switzerland [35, 41].

Many riparian plant species depend on continuous morphodynamic activity to form pioneer habitats and maintain active succession [30,34]. Compared to reaches with sufficient sediment supply, the morphodynamic processes in an erosional river widening are expected to be impaired. Bank erosion may be slowed down or inhibited due to inactive, coarse bed zones along the channel margins, as observed in experimental flumes [37] and the field [6, 42]. Lateral mobility of the stream may, therefore, be impaired by lack of sediment $[9,43]$. If gravel bars are not regularly reworked, they become fully vegetated and stabilize [22, 23, 44, 45]. The emergence and stabilization of bars due to reduced sediment supply reported, among others, by Lisle et al. [26] would likely promote rapid vegetation. River widenings with impaired topographic variability may also provide fewer refugia for aquatic organisms [46].

Madej et al. [6] described the channel response to increased sediment supply and noted that planform change in a formerly degrading reach only occurred when aggradation is sufficiently strong to fill the thalweg and form mid-channel bars. Whether the restoration of sediment transport, e.g. by gravel augmentation, can increase morphodynamic activity in river widenings is therefore strongly dependent on the current magnitude of incision [28]. However, Gaeuman et al. [47] found that gravel augmentation pulses can trigger additional topographic changes where material is deposited, and the initial widening of a dynamic river widening is a preferential deposition site.

To improve the prediction of the temporal evolution and ecological performance of dynamic river widenings, their morphological development will be studied in a laboratory flume of $4 \mathrm{~m}$ width and $30 \mathrm{~m}$ length. Froude similitude is applied at a scale of 1:20. The initial configuration is a straight channel with equilibrium slope. In a first test series, the suitability of different bank erosion inducement measures will be assessed under steady state conditions and sediment supply according to the transport capacity. In a second test series, the impact of variable degrees of sediment deficit on the morphological developement of dynamic river widenings will be examined. These test runs are composed of a steady state period followed by a single flood hydrograph. In addition to variable degrees of sediment deficit, the impact of sediment augmentation to the widening process in a sediment-starved stream will be investigated. In all the test runs, the topography of the river widening will be surveyed by repeated laser scans and top view photographs. The laser scan data will also be used to classify the bed surface according to its local grain size distribution. These measurements allow the quantification of the impact of sediment supply on the end width of the widening, its topographical variability, and its surface patchiness. The topographies obtained in the flume experiments will be transferred to a $2 \mathrm{D}$ hydrodynamic model to allow the rapid analysis of water depth and flow velocity depending on discharge. The results enable the mapping of habitats as a function of hydrological conditions and the assessment of their role as refugia during disturbance events such as floods or extended dry periods. In addition, the mixing processes between main channel and river widening will be visualized. 


\section{Conclusions}

The lateral mobility in dynamic river widenings along highly degraded, incised rivers may remain below expectations and initially formed gravel bars may rapidly become stabilized by vegetation. For rivers that are only weakly incised and exhibit a relatively high level of sediment transport, however, dynamic river widening seems to be a valuable restoration approach due to its self-sustained morphodynamic activity [48].

Nevertheless, dynamic river widening alone cannot restore degraded riparian ecosystems. Several studies found no positive correlation between increased habitat heterogeneity and the biodiversity of invertebrates or fish, thus challenging the 'habitat heterogeneity' paradigm [8, 49]. Palmer et al. [49] criticized the strong focus on physical habitat characteristics as there are multiple other stressors that act on a river system and while habitat heterogeneity is a prerequisite for a healthy riparian ecosystem, it may not be sufficient $[34,46,50]$.

These limitations should by no means discourage the implementation of dynamic river widenings, but rather motivate continued research to better incorporate this instrument into the larger context of river-floodplain connectivity [2]. Within this project in the research program Riverscapes, the morphological development of dynamic river widenings, the distribution of refugia, and possibilities to influence their occurrence will be studied by combining laboratory experiments and numerical modeling.

Acknowledgements - This research project is part of the interdisciplinary research program Riverscapes - sediment dynamics and lateral connectivity and the first author is financially supported by the Swiss Federal Office for the Environment (FOEN), Grant 16.0113.PJ / P501-1050.

\section{References}

[1] D. Vischer, Die Geschichte des Hochwasserschutzes in der Schweiz: von den Anfängen bis ins 19. Jahrhundert ('The history of flood protection in Switzerland: from the beginnings until the 19th century') (Bundesamt für Wasser und Geologie BWG, Bern, 2003), [in German]

[2] G. Kondolf, Environ. Manage. 21, 533 (1997)

[3] E. Wohl, B.P. Bledsoe, R.B. Jacobson, N.L. Poff, S.L. Rathburn, D.M. Walters, A.C. Wilcox, BioScience 65, 358 (2015)

[4] J.W. Emerson, Science 173, 325 (1971)

[5] N. Surian, M. Rinaldi, Geomorphology 50, 307 (2003)

[6] M.A. Madej, D.G. Sutherland, T.E. Lisle, B. Pryor, Geomorphology 103, 507 (2009)

[7] B. Hagin, in Comprehensive Renewable Energy (Elsevier, Oxford, 2012), pp. 343-354

[8] E. Wohl, S.N. Lane, A.C. Wilcox, Water Resour. Res. 51, 5974 (2015)

[9] M. Aufleger, B. Gems, R. Klar, Oesterr. Wasser- Abfallwirtsch. 64, 363 (2012), [in German]

[10] A.M. Kurth, M. Schirmer, Environ. Earth Sci. 72, 2065 (2014)

[11] P. Roni, T.J. Beechie, R.E. Bilby, F.E. Leonetti, M.M. Pollock, G.R. Pess, North Am. J. Fish. Manage. 22, 1 (2002)

[12] E.S. Bernhardt, M.A. Palmer, J.D. Allan, G. Alexander, K. Barnas, S. Brooks, J. Carr, S. Clayton, C. Dahm, J. Follstad-Shah et al., Science 308, 636 (2005)

[13] M. Church, Annu. Rev. Earth Planet. Sci. 34, 325 (2006)

[14] J.H. Mackin, Bull. Geol. Soc. Am. 59, 463 (1948)

[15] E.W. Lane, Proc. Am. Soc. Civ. Eng. 81 (1955)

[16] B.C. Eaton, R.G. Millar, Earth Surf. Process. Landf. 42, 994 (2017) 
[17] B.C. Eaton, M. Church, Earth Surf. Process. Landf. 36, 901 (2011)

[18] M.D. Harvey, C.C. Watson, J. Am. Water Resour. Assoc. 22, 359 (1986)

[19] G. Parker, P.C. Klingeman, Water Resour. Res. 18, 1409 (1982)

[20] B.C. Eaton, M. Church, R.G. Millar, Earth Surf. Process. Landf. 29, 511 (2004)

[21] R.G. Millar, Water Resour. Res. 36, 1109 (2000)

[22] W. Bertoldi, M. Welber, A. Gurnell, L. Mao, F. Comiti, M. Tal, Geomorphology 246, 178 (2015)

[23] W. Bertoldi, A. Siviglia, S. Tettamanti, M. Toffolon, D. Vetsch, S. Francalanci, Geophys. Res. Lett. 41, 7167 (2014)

[24] W.E. Dietrich, J.W. Kirchner, H. Ikeda, F. Iseya, Nature 340, 215 (1989)

[25] P.A. Nelson, J.G. Venditti, W.E. Dietrich, J.W. Kirchner, H. Ikeda, F. Iseya, L.S. Sklar, J. Geophys. Res. Earth Surf. 114, F02005 (2009)

[26] T. Lisle, F. Iseya, H. Ikeda, Water Resour. Res. 29, 3623 (1993)

[27] A.R. Bankert, P.A. Nelson, Sedimentology (2017)

[28] J.G. Venditti, P.A. Nelson, J.T. Minear, J. Wooster, W.E. Dietrich, J. Geophys. Res. Earth Surf. 117, F02039 (2012)

[29] L. Vonwiller, Numerical Modeling of Sediment Replenishment in Gravel-Bed Rivers (ETH Zürich, Zürich, to be published)

[30] A. Rollet, H. Piégay, S. Dufour, G. Bornette, H. Persat, River Res. Appl. 30, 939 (2014)

[31] T.E. Lisle, J.M. Nelson, J. Pitlick, M.A. Madej, B.L. Barkett, Water Resour. Res. 36, $3743(2000)$

[32] B.C. Eaton, M. Church, J. Geophys. Res. Earth Surf. 114, F01024 (2009)

[33] F. Friedl, Laboratory experiments on sediment replenishment in gravel-bed rivers (ETH Zürich, Zürich, 2017)

[34] S. Rohde, M. Schütz, F. Kienast, P. Englmaier, River Res. Appl. 21, 1075 (2005)

[35] H. Habersack, M. Klösch, Oesterr. Wasser- Abfallwirtsch. 64, 411 (2012), [in German]

[36] L. Hunzinger, Flussaufweitungen ('River Widenings') (ETH Zürich, Zürich, 1998), [in German]

[37] P. Requena, Seitenerosion in kiesführenden Flüssen ('Bank erosion in gravel-bed rivers') (ETH Zürich, Zürich, 2008), [in German]

[38] F. Friedl, V. Weitbrecht, R.M. Boes, in Proc. 36th IAHR World Congress (2015), pp. $1-12$

[39] R. Künzi, R. Kimmerle, Ing.biol. 27, 27 (2017), [in German]

[40] H. Ahmari, A.M.F. Da Silva, J. Hydraul. Res. 49, 718 (2011)

[41] VAW, Technical report 4234, ETH Zürich (unpublished), [in German]

[42] T.E. Lisle, M.A. Madej, in 3rd international workshop on Dynamics of gravel-bed rivers (1992), pp. 277-293

[43] M. Aufleger, A. Niedermayr, in River Flow 2004 (CRC Press, 2004), pp. 163-171

[44] E.J. Hickin, Can. Geogr. 28, 111 (1984)

[45] R.J. Thomas, J.A. Constantine, P. Gough, B. Fussell, River Res. Appl. 31, 1017 (2015)

[46] C. Weber, E. Schager, A. Peter, River Res. Appl. 25, 687 (2009)

[47] D. Gaeuman, R. Stewart, B. Schmandt, C. Pryor, Earth Surf. Process. Landf. 42, 2523 (2017)

[48] S. Schmutz, P. Jurajda, S. Kaufmann, A. Lorenz, S. Muhar, A. Paillex, M. Poppe, C. Wolter, Hydrobiologica 769, 67 (2016)

[49] M.A. Palmer, H.L. Menninger, E. Bernhardt, Freshwater Biol. 55, 205 (2010)

[50] N.R. Bond, P.S. Lake, Ecol. Manage. Restor. 4, 193 (2003) 